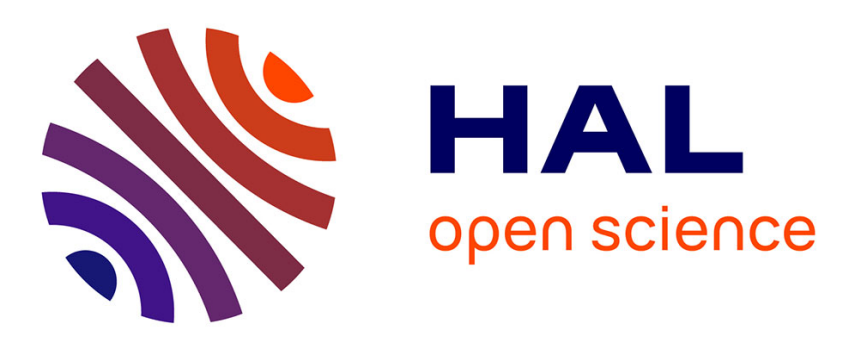

\title{
Crystal growth and characterization of the ruthenate superconducting compound: $\mathrm{Sr} 2 \mathrm{RuO} 4$
}

F. Servant, J. P. Brison, André Sulpice, Christine Opagiste, V. Madigou, P. Lejay

\section{To cite this version:}

F. Servant, J. P. Brison, André Sulpice, Christine Opagiste, V. Madigou, et al.. Crystal growth and characterization of the ruthenate superconducting compound: Sr2RuO4. Journal of Crystal Growth, 2005, 275, pp.739. 10.1016/J.JCRYSGRO.2004.11.086 . hal-00564392

\section{HAL Id: hal-00564392 \\ https://hal.science/hal-00564392}

Submitted on 10 Feb 2011

HAL is a multi-disciplinary open access archive for the deposit and dissemination of scientific research documents, whether they are published or not. The documents may come from teaching and research institutions in France or abroad, or from public or private research centers.
L'archive ouverte pluridisciplinaire HAL, est destinée au dépôt et à la diffusion de documents scientifiques de niveau recherche, publiés ou non, émanant des établissements d'enseignement et de recherche français ou étrangers, des laboratoires publics ou privés. 
Journal of Crystal Growth 275 (2005) e739-e743

\title{
Crystal growth and characterization of the ruthenate superconducting compound: $\mathrm{Sr}_{2} \mathrm{RuO}_{4}$
}

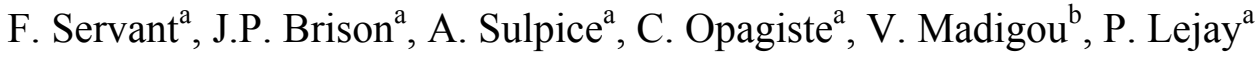 \\ ${ }^{a}$ CRTBT-CNRS, 25 avenue des Martyrs, BP 166, 38042 Grenoble Cedex 9, France \\ ${ }^{\mathrm{b}}$ L2MP-Site de Toulon, Bât. R, BP 132, 83957 La Garde Cedex, France
}

\begin{abstract}
$\mathrm{Sr}_{2} \mathrm{RuO}_{4}$ is a copper-free layered perovskite superconductor with the tetragonal $\mathrm{K}_{2} \mathrm{NiF}_{4}$-type structure. The precise nature of the pairing in the superconducting state of this material is still under debate. In this paper, we report about crystal growth and characterization of this compound. The crystals were grown by a floating zone technique using a light furnace equipped with double elliptical mirrors starting from off-stoichiometric $\mathrm{Sr}_{2} \mathrm{RuO}_{4}$. The crystals have been checked by X-ray diffraction and microanalysis. The superconducting properties were measured by AC-susceptibility, magnetization and specific heat. High crystalline quality centimetre-sized crystals have been grown and best crystals exhibit superconducting transitions at $\mathrm{Tc}=1.3 \mathrm{~K}$ (typical dimensions: $4.5 \mathrm{~mm}$ diameter and $70 \mathrm{~mm}$ length with the $\left(\begin{array}{lll}0 & 0 & 1\end{array}\right)$ axis perpendicular to growth direction). The unconventional superconductors are characterized by a drastic impurity effect on the superconducting properties. We try to establish a correlation between the defect concentration and the physical properties of $\mathrm{Sr}_{2} \mathrm{RuO}_{4}$.
\end{abstract}

PACS: 71.27.+a; 74.25.Ha; 74.70._b; 74.70.Pq

Keywords: A2. Floating zone technique; A2. Growth from melt; A2. Single crystal growth; B1. Oxides; B1. Perovskites; B2.Superconducting materials

\section{Introduction}

$\mathrm{Sr}_{2} \mathrm{RuO}_{4}$ still appears to be the only non cuprate layered-perovskite superconductor known to date. $\mathrm{Sr}_{2} \mathrm{RuO}_{4}$ shares the same $\mathrm{K}_{2} \mathrm{NiF}_{4}$ structure as the La-based cuprates superconductors. This structure can be built up by three perovskite monolayers stacked along the resulting c-axis where the layers 1 and 3 are $\mathrm{SrRuO}_{3}$ perovskite strontium-centred units, while layer 2 is ruthenium-centred. Removing two $\mathrm{RuO}_{2}$ layers lead to the $\mathrm{K}_{2} \mathrm{NiF}_{4}$ type structure [1-3]. For $\mathrm{n}=1$; this compound is a member of the Ruddlesden-Popper series: $\mathrm{Sr}_{n+1} \mathrm{Ru}_{n} \mathrm{O}_{3 \mathrm{n}+1}$ which includes $\mathrm{Sr}_{3} \mathrm{Ru}_{2} \mathrm{O}_{7}$ and $\mathrm{SrRuO}_{3}$, respectively, for $\mathrm{n}=2$ and $\infty$.

Research works performed, since its physical properties study [4,5], have firmly shown unconventional superconducting properties at almost $\mathrm{Tc}=1.5 \mathrm{~K}$ : As the heavy fermions systems, 
Journal of Crystal Growth 275 (2005) e739-e743

$\mathrm{Sr}_{2} \mathrm{RuO}_{4}$ is not s-wave type superconductor [6]. The main consequence is the non-magnetic impurity effect at very low concentration, which sharply drops the superconducting temperature to zero $[7,8]$.

In this paper, we report about the crystal growth experiment using the floating zone technique at ambient pressure in an image furnace. The single crystals are characterized by electronic microprobe analysis, X-ray powder and Laue diffraction, their mosaic has been measured by synchrotron diffraction.

The important problem of $\mathrm{Sr}_{2} \mathrm{RuO}_{4}$, in the sample preparation, is to obtain the superconducting state which appears to be extremely brittle due to a drastic impurity effect. The superconducting properties were measured by specific heat, alternative- current susceptibility using a standard mutualinductance technique in a $3 \mathrm{He}$ refrigerator and the magnetization measurements were performed on a SQUID magnetometer.

We discuss the relation between the superconducting properties and the presence of various defects in $\mathrm{Sr}_{2} \mathrm{RuO}_{4}$ single crystals.

\section{Experimental procedure}

Single crystals were grown by the floating zone method. Feed and seed rods were prepared by high temperature solid state reaction. Powders of $\mathrm{SrCO}_{3}(5 \mathrm{~N})$ and $\mathrm{RuO}_{2}(3 \mathrm{~N})$ were used as starting materials. Due to the high volatility of $\mathrm{RuO}_{2}$ during the growth process, the molar starting composition was 2:1.15 for $\mathrm{SrCO}_{3}$ and $\mathrm{RuO}_{2}$, respectively. The mixture was twice hydrostatically pressed at 10 kbars and sintered in air at $1300^{\circ} \mathrm{C}$ for $24 \mathrm{~h}$ with an intermediate grinding to improve the sample homogeneity. The cylindered samples were placed on rods of the same chemical composition to prevent contamination from the alumina crucible. The final rods dimensions were $5 \mathrm{~mm}$ length for $80 \mathrm{~mm}$ long.

A non commercial double-elliptical light furnace (equipped with two 1500W halogen lamps) has been used for growing the $\mathrm{Sr}_{2} \mathrm{RuO}_{4}$ single crystals. The atmosphere was composed of high quality oxygen (40\%) and argon (60\%) at room pressure. The feeding rod and the seed were inversely rotated at $10 \mathrm{rpm}$. To limit the $\mathrm{RuO}_{2}$ evaporation, the growth speed was typically kept between 2 and $4 \mathrm{~cm} / \mathrm{h}$.

\section{Results}

Several single crystals with typical size of $4-5 \mathrm{~mm}$ diameter and $10-70 \mathrm{~mm}$ length were successfully grown. During each process, two large $180^{\circ}$ opposite shiny facets were developed parallel to the growth direction (Fig. 1). Each growth has been checked by powder X-ray diffraction on crushed 
Journal of Crystal Growth 275 (2005) e739-e743

small parts of the crystal.

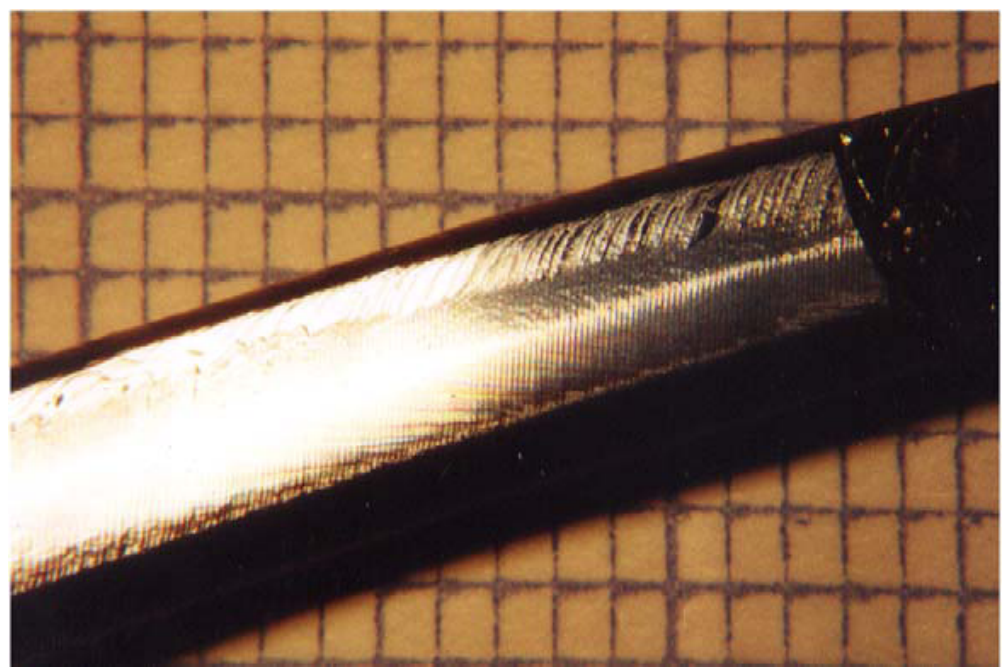

Fig. 1. Photo of $\mathrm{Sr}_{2} \mathrm{RuO}_{4}$ single crystal with a shiny facet perpendicular to the [0 0 l] direction.

The structural model of the K2NiF4-type structure (space group I4/mmm) has been used for the Rietveld refinements [9]. The following lattice constants were obtained: $a=b=3.873 \AA$ and $\mathrm{c}=12.745$ $\AA$ which are in agreement with those measured on the polycrystalline samples and from earlier results $[10,11]$. The single crystalline state has been checked by X-ray Laue back scattering. The shiny facets on the crystal surface, developed during the growth, correspond to a cleavage plane perpendicular to the $\left[\begin{array}{lll}0 & 0 & 1\end{array}\right]$ direction. Centimetre-sized single crystal $(5 \times 70 \mathrm{~mm})$ has been checked by neutron diffraction in ILL (Grenoble, France) for further experiments. A mosaic of 0.61 have been measured, for the whole volume, from a rocking curve on the $\left(\begin{array}{lll}0 & 0 & 2\end{array}\right)$ Bragg reflection. The same experiment, carried out at ESRF (Grenoble, France) by X-ray diffraction, (on a much smaller part of the crystal volume) gave a mosaic of 0.041 (Fig. 2).

To optimize the physical properties of $\mathrm{Sr}_{2} \mathrm{RuO}_{4}$, several parameters have been adjusted. First we studied, with a fixed rods chemical stoichiometry, the influence of the atmosphere composition at room pressure. A wide range of gas mixture has been tested : from $6 \%$ to $100 \%$ of oxygen in argon. It appeared that this parameter is not relevant to the superconducting properties of $\mathrm{Sr}_{2} \mathrm{RuO}_{4}$. We concluded that the oxygen partial pressure did not affect both the $\mathrm{RuO}_{2}$ evaporation level during the melt and the final oxygen stoichiometry of $\mathrm{Sr}_{2} \mathrm{RuO}_{4}$. It has to be noted that annealing the crystals at different temperature under various atmospheres never improved the superconducting properties of $\mathrm{Sr}_{2} \mathrm{RuO}_{4}$ too. The molar ratio of the starting material was 2:1.15 for, respectively, $\mathrm{SrCO}_{3}$ and $\mathrm{RuO}_{2}$. 
Journal of Crystal Growth 275 (2005) e739-e743

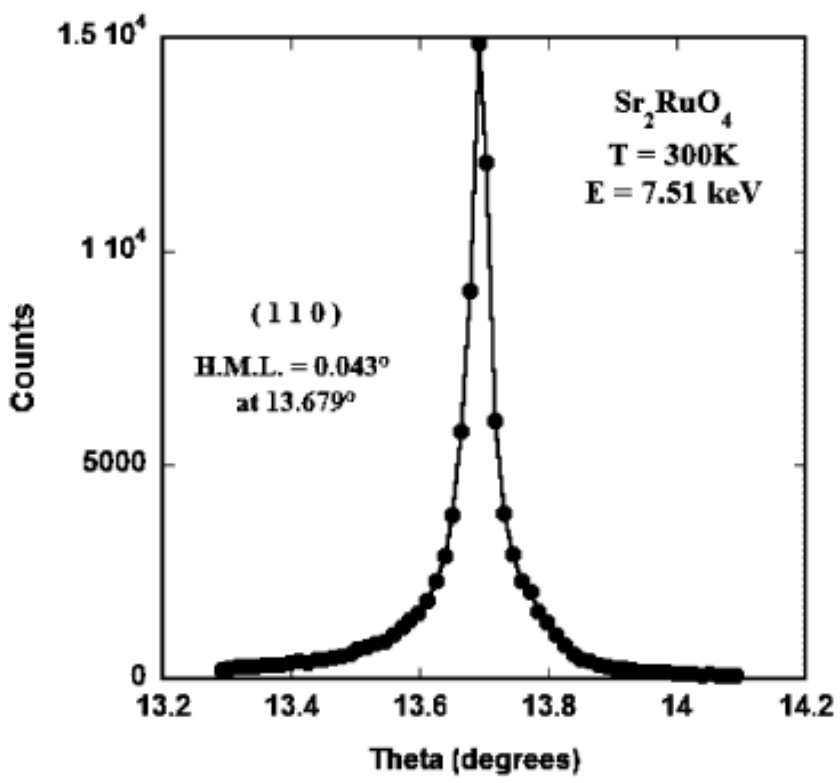

Fig. 2. (1 1 1 0) Bragg reflection measured at ESRF. The calculated mosaic is 0.041 .

To compensate precisely the $\mathrm{RuO}_{2}$ loss during melt, the growth rate has to be carefully adjusted to obtain a final pure phase. For this chemical composition, a fixed rods diameter (i.e. a constant volume of the melt) and a fixed rotation speed, we studied the influence of the pulling speed of the growth on the phase purity. The optimal speed, giving the best critical temperature, was $4 \mathrm{~cm} / \mathrm{h}$, Fig. 3 shows the influence of the growth speed on the superconducting temperature measured by ACsusceptibility.

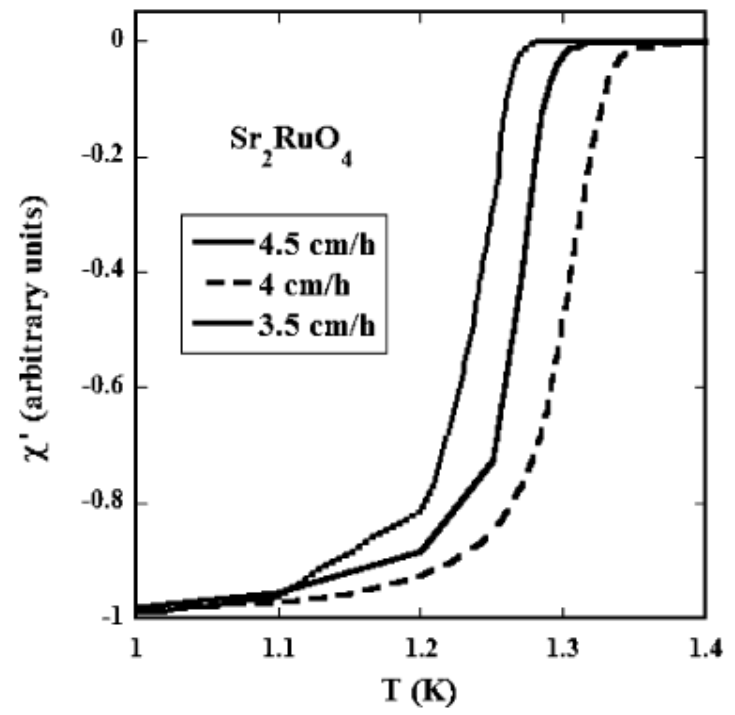

Fig. 3. Influence of the growth speed on the superconductivity. 
Journal of Crystal Growth 275 (2005) e739-e743

This rather rapid growth of the crystal was necessary to optimize the $\mathrm{RuO}_{2}$ stoichiometry. This could probably produce internal defects in the crystal but the measured mosaic on the crystals being very fairly good and more curiously annealing never improved the superconducting temperature. Due to the increase of the $\mathrm{RuO}_{2}$ concentration in the starting polycrystalline materials, and in regards to the pseudo-binary diagram $\left(\mathrm{SrO}-\mathrm{RuO}_{2}\right)$, it is possible to form $\mathrm{Sr}_{3} \mathrm{Ru}_{2} \mathrm{O}_{7}$ and $\mathrm{SrRuO}_{3}$ as impurity phases or epitaxial-like intergrowth.

With $\mathrm{Sr}_{2} \mathrm{RuO}_{4}$, those two last materials are in a crystallographic relation according to the Ruddlesden-Popper series. A very small amount of these phases could be detected by X-ray diffraction if the excess of $\mathrm{RuO}_{2}$ was not compensated by its evaporation during the growth (pulling speed dependent). However, AC-susceptibility measurements revealed no Tc dependence with a very tiny quantity of $\mathrm{Sr}_{3} \mathrm{Ru}_{2} \mathrm{O}_{7}$. On the other hand, in some crystals, magnetization measurements revealed traces of a ferromagnetic phase with an ordering Curie temperature of $165 \mathrm{~K}$. This was the signature of the presence of $\mathrm{SrRuO}_{3}$ in the material; even if it could not be detected by X-ray diffraction and MEB measurements. This ferromagnetic phase affects drastically the superconducting properties of $\mathrm{Sr}_{2} \mathrm{RuO}_{4}$. Fig. 4 represents the magnetization versus temperature for three different $\mathrm{Sr}_{2} \mathrm{RuO}_{4}$ single crystals, their superconducting temperatures are given in insert. For the non superconducting sample, grown with a starting composition of $2: 1.33$, the calculated ferromagnetic mass, assuming that the whole magnetic signal corresponded to $\mathrm{SrRuO}_{3}$, was $0.4 \%$ of the sample.

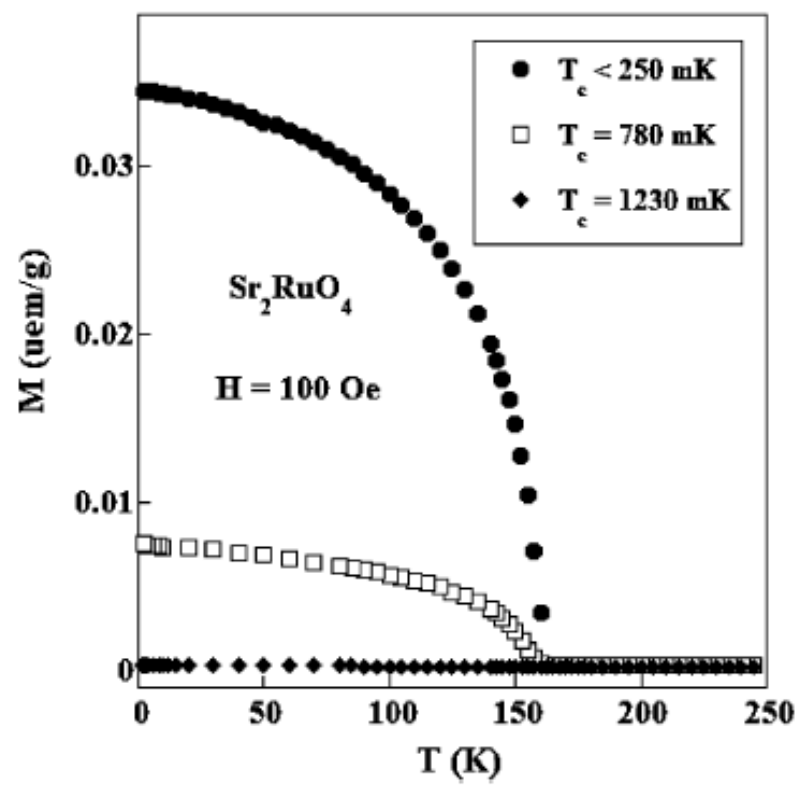

Fig. 4. Magnetization versus temperature for three different $\mathrm{Sr}_{2} \mathrm{RuO}_{4}$ single crystals.

For the crystal with $\mathrm{Tc}=0.78 \mathrm{~K}$, the decrease of the superconducting properties could be 
Journal of Crystal Growth 275 (2005) e739-e743

explained by the presence of $\mathrm{SrRuO}_{3}$ intergrowth undetectable by classical analysis (Fig. 5). For the crystal with the good $\mathrm{Tc}$ of $1.23 \mathrm{~K}$, the amount of $\mathrm{SrRuO}_{3}$ was negligible (o4 ppm). In the optimal crystal growth conditions, we obtained the superconducting properties which are described in Fig. 6, measured on a centimetre-sized $\mathrm{Sr}_{2} \mathrm{RuO}_{4}$ single crystal. The AC-susceptibility and the specific heat experiments showed a bulk transition at $\mathrm{Tc}=1.31 \mathrm{~K}$ with a width less than $0.2 \mathrm{~K}$.

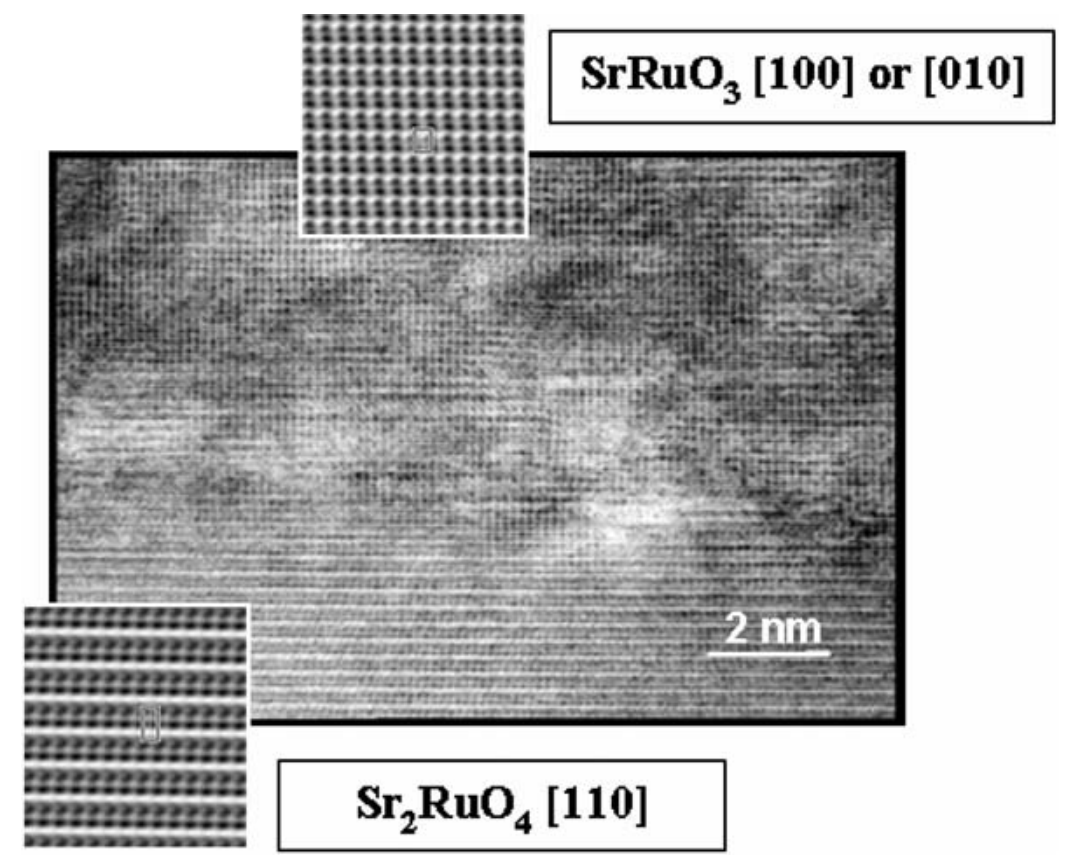

Fig. 5. High resolution transmission electronic microscopy of $\mathrm{Sr}_{2} \mathrm{RuO}_{4}$ crystal. SrRuO $\mathrm{O}_{3}$ have been detected in epitaxial growth. The Fourier transformed calculated pictures of each region are given in insert.

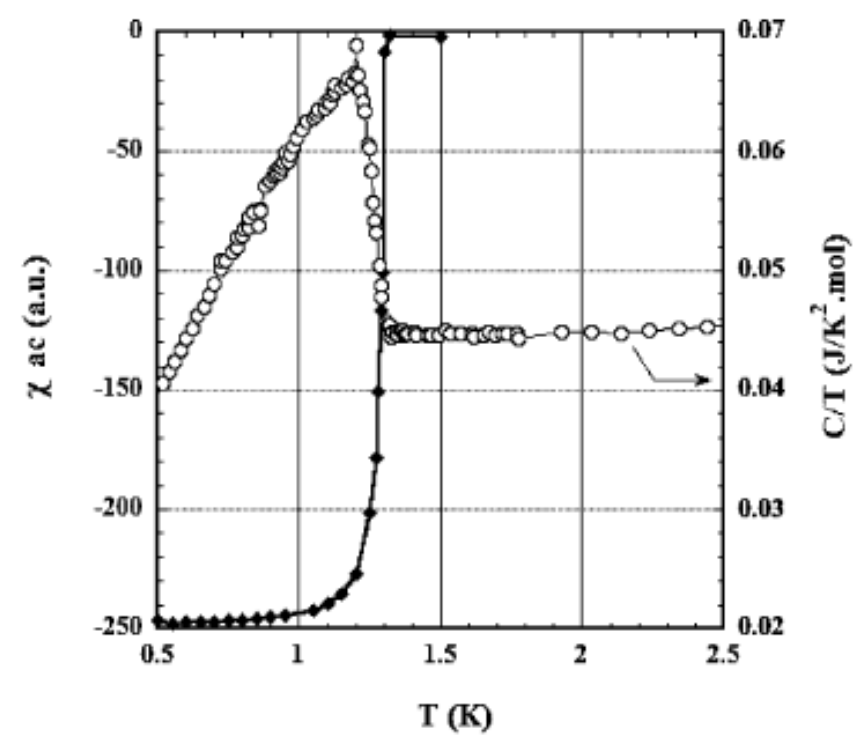

Fig. 6. AC-susceptibility and the specific heat measurements on centimetre-size as-grown $\mathrm{Sr}_{2} \mathrm{RuO}_{4}$ single crystal. 
Journal of Crystal Growth 275 (2005) e739-e743

\section{Conclusion}

We obtained high purity $\mathrm{Sr}_{2} \mathrm{RuO}_{4}$ single crystals by the floating zone technique in a light furnace with a sharp Tc up to $1.31 \mathrm{~K}$ measured on centimetre sized samples. For the highest Tc, the optimal starting composition of the rods was with $15 \% \mathrm{RuO}_{2}$ in excess and the growth speed of $4 \mathrm{~cm} / \mathrm{h}$. We observed that a very small amount of $\mathrm{SrRuO}_{3}$ is able to destroy the superconductivity of $\mathrm{Sr}_{2} \mathrm{RuO}_{4}$. Large single crystals with homogeneous superconducting properties for the whole volume have been obtained which allowed inelastic neutron scattering experiments [12-14].

\section{Acknowledgements}

We are grateful to J. Balay, A. Hadj-Azzem and J.M. Martinod, the technical and cryogenic staff of CNRS and CEA, Grenoble, France for expert assistance. We would also like to thank S. Raymond for neutron measurements.

\section{References}

[1] L. Walz, F. Lichtenberg, Acta Crystallogr. C 49 (1993) 1268.

[2] J.J. Randall Jr., L. Katz, R. Ward, J. Am. Chem. Soc. 79 (1957) 266.

[3] J.J. Randall, R. Ward, J. Am. Chem. Soc. 81 (1959) 2629.

[4] G. Cao, S. McCall, J.E. Crow, Phys. Rev. B 55 (1997) R672.

[5] S.I. Ikeda, Y. Maeno, Physica B 259-261 (1999) 947.

[6] K. Ishida, H. Mukuda, Y. Kitaoka, K. Asayama, Z.Q. Mao, Y. Mori, Y. Maeno, Nature 396 (1998) 6712.

[7] Z.Q. Mao, Y. Maeno, H. Fukasawa, Mater. Res. Bull. 35 (2000) 1813.

[8] A.P. Mackenzie, R.K.W. Haselwimmer, A.W. Tyler, G.G. Lonzarich, Y. Mori, S. Nishizaki, Y. Maeno, Phys. Rev. Lett. 80 (1998) 151.

[9] H.M. Rietveld, J. Appl. Crystallogr. 2 (1969) 65.

[10] L.P. Hatch, Am. Scientist 41 (1953) 401.

[11] G.L. McCarthy, Nucl. Technol. 32 (1977) 92.

[12] F. Servant, S. Raymond, B. Fak, P. Lejay, J. Flouquet, Solid State Commun. 116 (2000) 489.

[13] F. Servant, B. Fak, S. Raymond, J.P. Brison, P. Lejay, J. Flouquet, Phys. Rev. B 65 (2002) 184511 .

[14] B. Fak, S. Raymond, F. Servant, P. Lejay, J. Flouquet, cond-mat 0308558 (2003 